\title{
Generating Appropriate Technologies for Health Equity: José Luis Fernández Yero, MD, PhD Director, Immunoassay Center, Havana
}

\author{
By Gail Reed, MS
}

Immunologist by training, Dr Fernández Yero began his career in medical technology at the National Center for Scientific Research in Havana, working at the behest of several hospitals to develop the first Cuban alpha-fetoprotein test. It was the 1970s, a time when a single public health system was taking shape in Cuba and many of the main poverty-related social determinants of health had been tackled. "We were looking for technologies of the future," he says, "to see what we could do that could be applied throughout a national public health system." Sixteen generations of equipment later, Dr Fernández Yero heads the 21-year-old Immunoassay Center, a leader in the field of medical technology for population health. The road traveled has not been an easy one, lack of resources threatening delays and detours along the way. He shares his thoughts with MEDICC Review on his work, the meaning of appropriate technology and the challenges he foresees ahead.

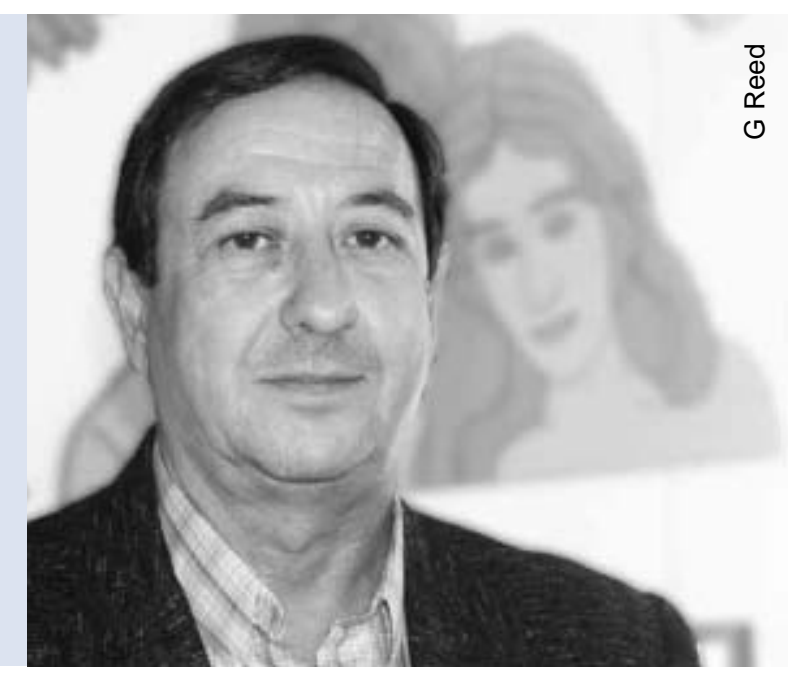

\section{MEDICC Review: What makes a particular technology} 'appropriate'?

José Luis Fernández Yero: Broadly speaking, I would say technology is appropriate when it is accessible to the people who need it in any particular country or region; when it increases health care coverage as efficiently as possible within the resources at hand. I say 'as efficiently as possible' since appropriate technology-at least in our own case-has a greater dose of justice than of economics. That's the bottom line. Because if you are only guided by economics, then the cheapest will always be the 'best', and less economical but more effective technologies and drugs will never have a chance.

At the same time, it's a tough balance to achieve, since efficiency also makes ethical sense: health planners have to use resources in the most rational, optimal way in order to preserve the right to health for the greatest number of people. In the context of social justice, poor resource management implies wasteful spending on some to the detriment of others.

Assessments of the social determinants of health reveal that poor people, uneducated people and people living in marginalized neighborhoods are more likely to get sick and to die than those who are better off. This tells us that everywhere efforts should prioritize these people's health through prevention strategies, supported by appropriate technologies.

In our experience, sustainable health depends more on health promotion and disease prevention-including application of technologies for broad health coverage that are appropriate for the socioeconomic environment-than on application of complex technologies or the latest models advertised by market-driven transnational manufacturers.
MEDICC Review: Where are most innovations in appropriate technology developed?

José Luis Fernández Yero: For the most part, 'appropriate technology' comes from industrialized countries and is intended for us, in developing countries. Unfortunately, the solutions proposed are not usually what we need. It's difficult for someone in Boston to imagine what's needed in Maisí [the eastern tip of Cuba-eds.].

These researchers tend to imagine that we have limited education or limited intellectual capabilities for assimilating new technologies when the real problem is often limited infrastructure. For example, they see centralization of technology as the answer to many problems. But let's say laboratory blood testing were to be centralized. That presupposes an efficient postal system to get samples to the lab, which you won't find in Cuba, Latin America or Africa. So, in this case, such a centralized laboratory model is bound to fail. And there are countless other well-intentioned examples.

We have to devise our own technologies, by developing countries for developing countries, to be applied appropriately. That is the other key: solving health problems is as much about how you apply the technology as it is about the technology itself. Take infant mortality in Cuba as a health outcome: in 2008, it dropped to below 5 deaths per 1,000 live births. We don't have the same high-tech capabilities as the United States or Canada, but we have lower infant mortality -in part because we have been able to bring the necessary technology closer to all pregnant women and newborns.

MEDICC Review: What has the Immunoassay Center's R\&D contributed to better health outcomes in Cuba over the years?

José Luis Fernández Yero: We began, as you know, as a team working to develop an economical alpha-fetoprotein screening 
test to detect fetal malformations, allowing women and couples to make an informed decision about continuing pregnancy, contributing both to a reduction in infant mortality and better medical attention for children born with problems.

Since then, we have developed 28 diagnostic tests and 16 generations of equipment to screen for conditions ranging from congenital hypothyroidism and phenylketonuria (PKU) in newborns, to HIV, hepatitis and dengue. Our leading products are the ultramicroanalytic system (SUMA) and reagent kits (UMELISA and UMTEST). These diagnostic tools are closely linked to public health programs, such as maternal-child health, and to epidemiological surveillance for infectious diseases. For example, in 1986, Cuba became the second country in the Americas (after Canada) to provide full newborn screening coverage for congenital hypothyroidism. Today, all Cuban infants are tested at birth for hypothyroidism, PKU, congenital adrenal hyperplasia, biotinidase deficiency and galactosemia. These tests alone have been decisive in guaranteeing a better quality of life for hundreds of Cuban children and their families.

I should mention that we regularly monitor diagnostic kits and reagents for accuracy of results, and all our laboratories in Cuba and Latin America participate in international monitoring, such as the US Centers for Disease Control Newborn Screening Quality Assurance Program's proficiency testing panels.

Our Center is also responsible for protecting the country's blood supply, screening and certifying all blood donations.

In all, some 50 million tests have been carried out with the Center's technology, which is decentralized in 181 laboratories throughout the public health system, reaching every municipality in the country. Another 55 laboratories are located in research institutions and armed forces health facilities.

\section{MEDICC Review: How does the Center fi- nance its research, development and pro- duction?}

José Luis Fernández Yero: We stopped receiving a budget from the government at the beginning of the economic crisis in the early 1990s. Since then, we finance our own R\&D, as well as production, through sales and exports. In 2008 , we grossed US $\$ 22$ million. That is being re-invested and has already made possible the addition of 42 laboratories in Cuba in 2008, and another 64 will be added in 2009. As a result, some municipalities will now have three labs. This is important, since the technology is continually moving closer to the community.

We sell our products to the Cuban health system at reduced prices in local currency and to other countries at prices well below those charged by other manufacturers. Our main contracts are with Mexico, Colombia, Venezuela, Bolivia, Brazil, Argentina and China. Now, we're extending our market into Paraguay, Peru and Ecuador.
We have also set up labs in several countries, including Argentina (43), Mexico (88) and Angola (80). This has expanded screening programs there, especially for pregnant women and newborns.

\section{MEDICC Review: What is on the horizon for the Center's work?}

José Luis Fernández Yero: A few years ago, the Ministry of Public Health asked us to begin working on non-communicable chronic conditions, which are the main health problem in Cuba today. Some $49 \%$ of Cubans die from metabolic syndrome and another $38 \%$ from cancer. Progress in early detection and control of these illnesses will mean longer lives and better quality of life for millions of Cubans.

One example is prostate cancer, responsible for the death of 2,540 Cuban men in 2007. We have now developed our own prostatespecific antigen (PSA) test for early detection and are gradually extending its availability across the country for annual testing of all men aged 50 and over. In other words, we now have a tool for mass screening as opposed to limited availability of the imported test, which was costing us about US \$14 apiece. In addition, since all that is required is a blood sample, rather than a rectal exam, men will be more willing to be tested. Over half of men with prostate cancer can be cured if the disease is caught early, meaning that we have the potential of saving 1,000 lives a year once this test is available nationally. What's more, about $95 \%$ of these tests will be negative, and, because the laboratories are located in each municipality, the results are known immediately, giving peace of mind to thousands.

Another example is colon cancer: we're working on a test to measure human hemoglobin in feces, which is more precise than the current test detecting any kind of blood in feces. This will allow us to make better early diagnoses of this cancer, which affects Cuban women more than men. About 1,000 women in our country die annually from colon cancer, but approximately $80 \%$ could be saved if diagnosed early enough.
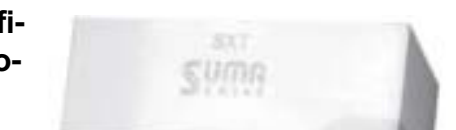

In terms of other chronic conditions, we're currently registering a test for quantitative measurement of microalbuminuria, which is important for diseases associated with vascular damage, especially chronic kidney disease.

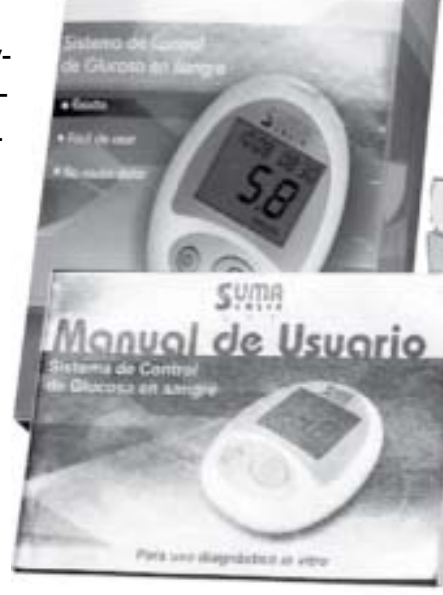

Finally, a glucometer developed by our Center (SUMAsensor) is now being introduced in Cuba

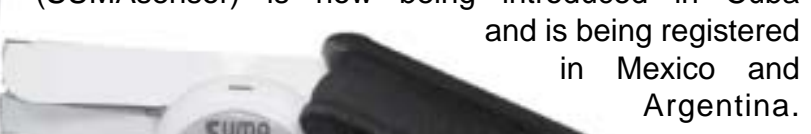

The SUMAsensor "tropical glucometer" developed by the Cuban Immunoassay Center in Havana. 
Cuban Immunoassay Technology in the National Public Health System*

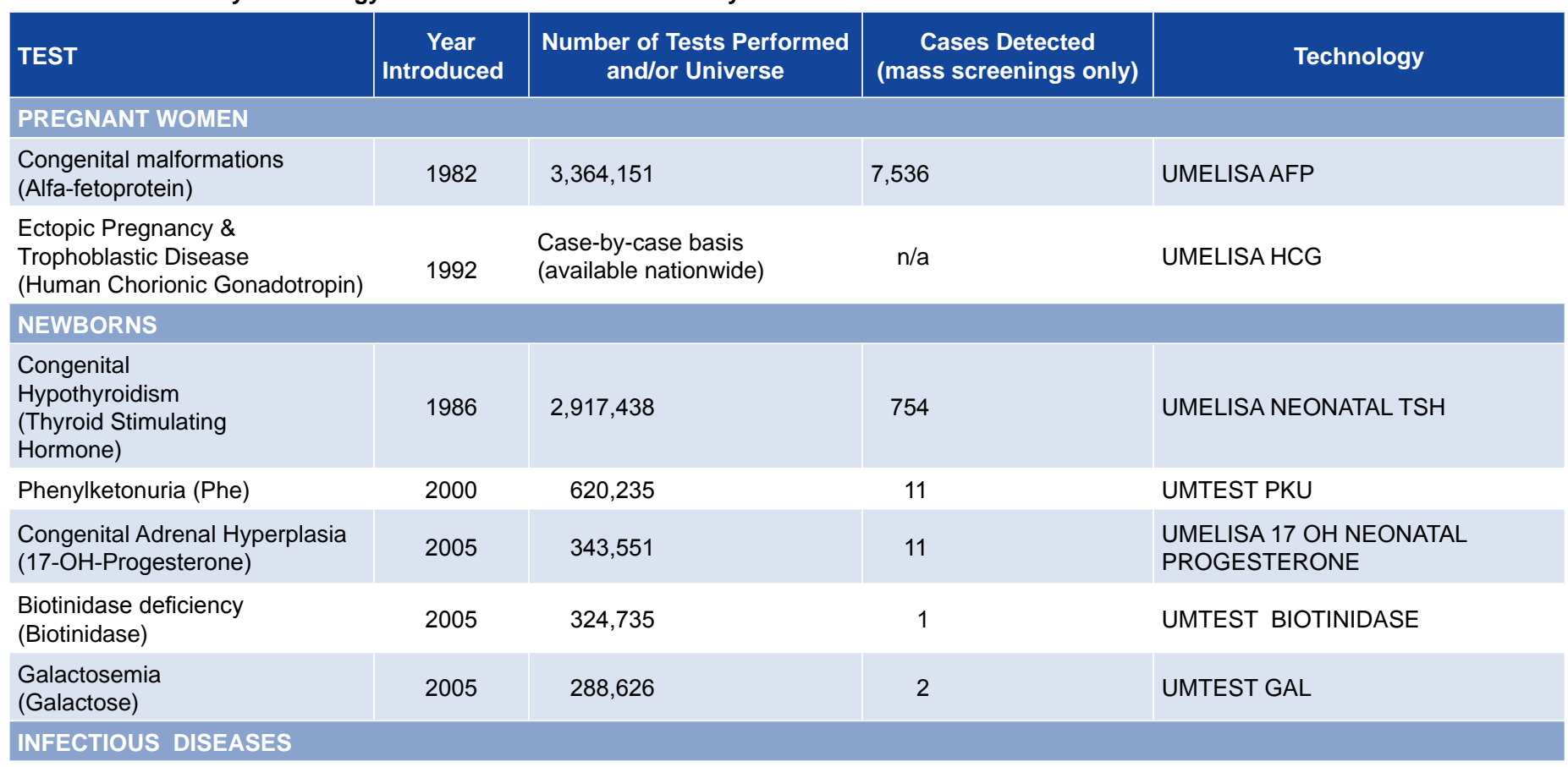

$\begin{array}{lll}\text { HIV-AIDS } & 1988 \quad \begin{array}{l}\text { (including blood donors, } \\ \text { (anti-HIV1\&2) }\end{array} & \begin{array}{l}\text { gregnant women, and for } \\ \text { general epidemiological } \\ \text { surveillance) }\end{array}\end{array}$

Hepatitis B

(HBsAg \& other serological markers)

1980 (including blood donors, pregnant women, and for general epidemiological surveillance)

\section{$8,586,826$}

\section{Hepatitis C}

(anti-HCV)

1992

(including blood donors and for general epidemiological surveillance)

\begin{tabular}{|c|c|l|}
\hline $\begin{array}{l}\text { Dengue } \\
\text { (IgM antibodies) }\end{array}$ & 1995 & $\begin{array}{l}\text { Suspected cases during } \\
\text { outbreaks }\end{array}$ \\
\hline $\begin{array}{l}\text { Leprosy } \\
\text { (IgM antibodies) }\end{array}$ & 1993 & Suspected cases \\
\hline $\begin{array}{l}\text { Chagas } \\
\text { (IgG antibodies) }\end{array}$ & 1994 & $\begin{array}{l}\text { All travelers to Cuba from } \\
\text { endemic countries or regions }\end{array}$ \\
\hline
\end{tabular}

\section{Tetanus}

(IgG anti-toxin)
1996 Blood donors
10,615 seropositive tests

Of blood donors: $0.63 \%$

UMELISA HIV $1+2$ RECOMBINANT

Non-specific reactivity among blood donors: $0.97 \%$

Confirmed cases among blood donors: 70,590 ( $0.74 \%$ of blood donors)

UMELISA HBSAg PLUS HBSAg CONFIRMATORY TEST UMELISA ANTI- HBSAg

UMELISA ANTI-HBC

UMELISA ANTI-HBC IgM

Reactivity in blood donors:

$0.85 \%$

UMELISA HCV

$\mathrm{n} / \mathrm{a}$

UMELISA DENGUE IgM PLUS

$\mathrm{n} / \mathrm{a}$

UMELISA HANSEN

$\mathrm{n} / \mathrm{a}$

UMELISA CHAGAS

Donations with required titers used for production

\section{NON-COMMUNICABLE CHRONIC CONDITIONS}

\section{Diabetes Mellitus} (blood glucose)

\section{Prostate cancer}

(Prostate-Specific Antigen)

Atopic diseases

(Total lgE)

*updated October 2008

Source: Immunoassay Center, Havana. of human tetanus immunoglobulin

Currently being rolled out through primary care services

\section{SUMASensor}

(Glucometer)

UMELISA TETANUS

UMELISA PSA

63,606 n/a

$\mathrm{n} / \mathrm{a}$

UMELISA IgE 
We sell it very economically to the Cuban public health system and internationally at about $60 \%$ the price of other similar equipment.

The Cuban-developed glucometer for diabetic patients is specially designed for tropical climates (each dipstick packaged separately with an enclosed dehumidifier sachet) and can be regulated for skin thickness (important for children). Test results appear in 25 seconds.

We've begun distributing it through hospitals (starting with ICUs and neonatal units) and also at the primary care level in those places where the annual family physical checkup is being piloted. This exam offers a more integrated approach to preventive care, taking into consideration genetic and environmental factors, and the gloucometer is being included in the technology for this program.

Eventually, each severe diabetic will have their own glucometer at home, and the neighborhood family doctor-and-nurse offices will have them to measure the glucose levels of other diabetics two to three times a week. This will mean a tremendous improvement in quality of life for diabetic patients, who now have to go to a polyclinic to have their blood tested.

\section{MEDICC Review: What are the Center's biggest challenges now?}

José Luis Fernández Yero: Organizing and managing an efficient network of the 181 laboratories located in all the country's municipalities. People are always more difficult than molecules.

Looking further ahead, we have to think of personalizing tests for susceptibility to certain diseases and conditions-but personalizing them for 11 million people, not just a few individuals. Susceptibility can then be included in each person's clinical history, along with other risk factors. This means introducing nanotechnology at the population health level for lower-cost active screening, facilitating detection of many conditions with a single assay.

We continue to dream and to push forward, propelled by the pressing problems in Cuba and in other developing countries where we think we can make a contribution. - - p 